\title{
New and emerging contraceptives: a state-of-the-art review
}

This article was published in the following Dove Press journal:

International Journal of Women's Health

19 February 2014

Number of times this article has been viewed

\author{
Luis Bahamondes \\ MValeria Bahamondes \\ Human Reproduction Unit, \\ Department of Obstetrics and \\ Gynaecology, Faculty of Medical \\ Sciences, University of Campinas and \\ National Institute of Hormones and \\ Women's Health, Campinas, SP, Brazil
}

Correspondence: Luis Bahamondes Caixa Postal 6I8I, I3084-97I,

Campinas, SP, Brazil

Tel +55 I9 32892856

Fax +551932892440

Email bahamond@caism.unicamp.br
Background: The first hormonal contraceptive was introduced onto the market in several countries 50 years ago; however, the portfolio of contraceptive methods remains restricted with regards to their steroid composition, their cost, and their ability to satisfy the requirements of millions of women/couples in accordance with their different reproductive intentions, behaviors, cultures, and settings.

Methods: A literature review was conducted using Medline, Embase, and Current Contents databases, up to September 1, 2013 to identify publications reporting new contraceptives in development using combinations of the search terms: contraception, contraceptives, oral contraceptives, patch, vaginal ring, implants, intrauterine contraceptives, and emergency contraception (EC). Also, several experts in the field were also consulted to document ongoing projects on contraception development. Additionally, the Clinicaltrial.gov website was searched for ongoing studies on existing contraceptive methods and new and emerging female contraceptives developed over the past 5 years. Information was also obtained from the pharmaceutical industry.

Results: Early sexual debut and late menopause means that women may require contraception for up to 30 years. Although oral, injectable, vaginal, transdermal, subdermal, and intrauterine contraceptives are already available, new contraceptives have been developed in an attempt to reduce side effects and avoid early discontinuation, and to fulfill women's different requirements. Research efforts are focused on replacing ethinyl-estradiol with natural estradiol to reduce thrombotic events. In addition, new, less androgenic progestins are being introduced and selective progesterone receptor modulators and new delivery systems are being used. In addition, research is being conducted into methods that offer dual protection (contraception and protection against human immunodeficiency virus transmission), and contraceptives for use "on demand." Studies are also investigating non-hormonal contraceptive methods that have additional, non-contraceptive benefits.

Conclusion: The most pressing need worldwide is, first, that the highly effective contraceptive methods already available should be affordable to most of the population and also that these methods should fulfill the needs of women of different ages and with different reproductive requirements. The development of new contraceptive methods should also take advantage of the knowledge obtained over the past 30 years on gamete physiology and gamete interaction to avoid the use of steroid compounds.

Keywords: emerging contraceptives, patch, vaginal ring, intrauterine devices, spray, emergency contraceptives

\section{Background}

Particularly in the Western hemisphere, girls are beginning their sexual life much earlier than in the past, while the onset of menopause is later than ever before and the 
average woman has no more than two children. Therefore, taking into account the time involved in trying to conceive, the outcome is that many women need contraception for around 28-30 years of their lives. Additionally, many women are now aware that some of the contraceptive methods available also offer non-contraceptive benefits. ${ }^{1}$

Slightly more than 50 years have elapsed since the introduction of the first combined oral contraceptive (COC). In 1961, the US Food and Drug Administration approved Enovid $10 \mathrm{mg}$ (G. D. Searle \& Co., Palo Alto, CA, USA) (9.85 mg of norethynodrel and $150 \mu \mathrm{g}$ of mestranol) for contraceptive use. This was followed by Enovid $5 \mathrm{mg}$ ( $5 \mathrm{mg}$ of norethynodrel and $75 \mu \mathrm{g}$ of mestranol). In that same year, the first COC was launched in Germany (Anovlar; norethindrone acetate $4 \mathrm{mg}$ and ethinyl estradiol [EE] $50 \mu \mathrm{g}$; Schering AG, BerlinWedding, Germany). ${ }^{2}$ Nevertheless, many women remain underserved insofar as contraception is concerned, and unplanned pregnancy is estimated around $50 \%$ of pregnancies in both developed and in developing countries. ${ }^{3}$ This figure is at odds with the UN Millennium Development Goal \#5, which advocates universal access to contraception. ${ }^{4}$

Although history shows that birth control has been used in one form or another for thousands of years, ${ }^{5}$ the principal contribution of modern contraceptives, in addition to avoiding pregnancy, is in permitting reproduction to be differentiated from sexual intercourse and in empowering women by giving them the right to choose privately whether or not to use contraception. Nevertheless, despite the fact that since the first COC was launched many other drugs and innovative delivery systems have been developed, there remains a need for further research and new developments. Indeed, the principal factor involved in the need to develop new contraceptive methods is that existing methods may not be appropriate or ideal for all women due to their side effects, changes in bleeding patterns, changes in mood or libido, or because of opposition from the woman's partner.

Additionally, different contraceptives may be required as a function of the woman's age or reproductive desires (spacers versus limiters). Many women are looking for contraceptive methods with non-contraceptive benefits and others, principally in the Western hemisphere, want contraceptive methods that will allow them to control their menstrual bleeding or eliminate it altogether. Moreover, many women may be dissatisfied with the contraceptive method they are currently using because of its cost, because of misconceptions about the method, religious issues or concerns regarding their health, and future fertility. ${ }^{6}$ However, there is an ongoing debate in the medical community and among policy makers and stakeholders regarding whether research and development of new contraceptive methods is really necessary. It is argued that the focus should be on making sure that the existing contraceptive methods are available worldwide and at an affordable cost to the millions of women without access to contraceptive methods. ${ }^{7}$ This review focuses on new emerging hormonal contraceptives for women. ${ }^{8,9}$

\section{New contraceptive methods recently launched in different markets and those currently being developed Combined methods cocs}

Since the principal reason given by COC users for discontinuing the method is side effects and their main concern is the risk of venous thromboembolism (VTE), pharmaceutical companies have introduced new formulations aimed at increasing tolerability and reducing side effects. ${ }^{10}$ The new formulations launched have lower doses of estrogen, and EE has been replaced by more "physiological" forms of estrogen such as $17 \beta$-estradiol $\left(\mathrm{E}_{2}\right)$ or $\mathrm{E}_{2}$-Valerate $\left(\mathrm{E}_{2} \mathrm{~V}\right) .{ }^{11-13}$ In addition, new progestins have been introduced. ${ }^{14-17}$

Many attempts have been made over a considerable amount of time to replace EE with $\mathrm{E}_{2}$ in COCs; however, bleeding control was unsatisfactory, ${ }^{11-13}$ particularly in monophasic and biphasic regimens. To improve bleeding control in studies with COCs containing $\mathrm{E}_{2}$, two new COCs were developed. In one, $\mathrm{E}_{2} \mathrm{~V}$ was combined with dienogest (DNG) in a four-phase regimen consisting of step-down doses of $\mathrm{E}_{2} \mathrm{~V}$ and step-up doses of DNG. Accordingly, $\mathrm{E}_{2} \mathrm{~V} / \mathrm{DNG}$ is given in a 28-pill cycle: $\mathrm{E}_{2} \mathrm{~V} 3 \mathrm{mg}$ on days 1 and $2, \mathrm{E}_{2} \mathrm{~V}$ $2 \mathrm{mg} / \mathrm{DNG} 2 \mathrm{mg}$ on days 3-7, E $2 \mathrm{~V} 2 \mathrm{mg} / \mathrm{DNG} 3 \mathrm{mg}$ on days $8-24, E_{2} V 1 \mathrm{mg}$ on days 25 and 26 and placebo on days 27 and 28. It has to be taken into account that $1 \mathrm{mg}$ of $\mathrm{E}_{2} \mathrm{~V}$ contains $0.76 \mathrm{mg}$ of $\mathrm{E}_{2}$. DNG is a progestin that exerts a potent effect on the endometrium ${ }^{18}$ and the four-phasic regimen results in good cycle control. In addition, the estrogen dominance in the first days of the cycle assures endometrial proliferation and sensitivity to the mid-cyclic effect of the progestin, while DNG provides stability to the endometrial stroma at the end of the cycle.

Previous studies have shown that after oral intake of these two steroids, $\mathrm{E}_{2} \mathrm{~V}$ is rapidly hydrolysed and converted to $\mathrm{E}_{2}$ during absorption in the gastrointestinal tract ${ }^{19}$ while DNG is almost completely absorbed, resulting in wide distribution 
and high bioavailability. ${ }^{20,21}$ Furthermore, DNG was found to have some of the properties of progesterone $(\mathrm{P})$ without exerting any effect on the metabolic or cardiovascular systems and with anti-androgenic activity and no glucocorticoid, anti-mineralocorticoid or anti-estrogenic effects. ${ }^{22}$ In addition, $\mathrm{E}_{2}$ binds to sex hormone-binding globulin (SHBG) and is widely distributed, with almost $2 \%$ of $\mathrm{E}_{2}$ being free and bioactive. ${ }^{23}$ The $\mathrm{E}_{2} \mathrm{~V} / \mathrm{DNG}$ COC provides consistent levels of $\mathrm{E}_{2}$ throughout the pill cycle. ${ }^{24-28}$ This new COC has already been launched in various countries (Qlaira ${ }^{\circledR}$; Natazia ${ }^{\circledR}$; Bayer AG, Leverkusen, Germany).

The efficacy of this new COC was evaluated in 1,377 women $^{29}$ who completed 23,368 women-months of exposure. The unadjusted and adjusted Pearl Index was 0.73 and 0.34 , respectively. In a subgroup of 998 young women of 18-35 years of age, the unadjusted and adjusted Pearl Index was 0.94 and 0.40, respectively. However, despite a high satisfaction rate, 917 women $(66.6 \%)$ reported at least one side effect, although the most commonly reported complaints were considered mild. Insofar as the $20 \%$ of reported adverse events are concerned, the most common were breast pain and/or discomfort, acne, headache, metrorrhagia, and weight gain.

A double-blind randomized clinical trial (RCT) involving 798 women ${ }^{26}$ compared bleeding patterns and cycle control of this new $\mathrm{COC}\left(\mathrm{E}_{2} \mathrm{~V} / \mathrm{DNG}\right)$ with those of a monophasic COC containing EE $20 \mu \mathrm{g} /$ levonorgestrel (LNG) $100 \mu \mathrm{g}$. Only one pregnancy occurred in the group allocated to the EE/LNG COC. With respect to bleeding patterns, the women allocated to the $\mathrm{E}_{2} \mathrm{~V} / \mathrm{DNG} \mathrm{COC}$ had significantly fewer bleeding/spotting days compared to the other group in the first 6 months of use. Scheduled withdrawal bleeding occurred in $77.7 \%-83.2 \%$ and in $89.5 \%-93.8 \%$ of cycles in users of the $\mathrm{E}_{2} \mathrm{~V} / \mathrm{DNG}$ and $\mathrm{EE} / \mathrm{LNG}$ combinations, respectively $(P<0.0001)$. Amenorrhea was more common in users of the $\mathrm{E}_{2} \mathrm{~V} / \mathrm{DNG} \mathrm{COC}$ than in those using the EE/LNG COC, with adverse effects occurring in around $9 \%$ of women in both groups.

There are no large studies regarding the new $\mathrm{COC}$ and VTE; however, information on this pill's effects on metabolic patterns is limited; nevertheless, there is evidence of a $7.9 \%$ increase in high density lipoprotein cholesterol and a $6.5 \%$ decrease in low density lipoprotein cholesterol. ${ }^{27}$ In addition, there were no essential changes in prothrombin fragment $1+2$ and D-dimer levels $(-0.6 \% \pm 30.3 \%$ and $-2.1 \% \pm 43.5 \%$, respectively) and changes in SHBG and carbohydrate metabolism were generally less pronounced when compared to $\mathrm{EE} / \mathrm{LNG} \mathrm{COC}^{27}$
In addition to its contraceptive effect, this new COC was also approved and launched in the US market for the treatment of heavy menstrual bleeding (HMB). Although there is no evidence that any other COC effectively reduces $\mathrm{HMB}$, this remains a common indication for COCs. ${ }^{28}$ However, the available information shows that the $\mathrm{E}_{2} \mathrm{~V} / \mathrm{DNG} \mathrm{COC}$ is indeed effective for the treatment of HMB. ${ }^{28,29}$ A USbased study reported that HMB was successfully resolved in $43.8 \%$ (95\% confidence interval [CI]: 32.7\%-55.3\%) of users of the $\mathrm{E}_{2} \mathrm{~V} / \mathrm{DNG}$ COC compared to placebo $(4.2 \%$; 95\% CI: $0.5 \%-14.3 \%$ ), with a reduction in mean blood loss of $-353 \mathrm{~mL}$ versus $-130 \mathrm{~mL}(P<0.0001)$ when $\mathrm{E}_{2} \mathrm{~V} / \mathrm{DNG}$ users were compared to women using a placebo. ${ }^{29}$ Results also showed a significant improvement in hemoglobin, hematocrit, and ferritin levels. ${ }^{29}$ Another study conducted in several European countries and in Australia showed similar results. ${ }^{28}$ Both studies confirmed the usefulness of the new COC for the treatment of idiopathic HMB.

Another COC containing a natural estrogen $\left(17 \beta-\mathrm{E}_{2}\right)$ and a new progestin (nomegestrol acetate [NOMAC]) (Zoely ${ }^{\circledR}$; Merck \& Co, Inc., Whitehouse Station, NJ, USA) has already been launched in several European and Latin American countries. Two large RCTs were conducted to evaluate the efficacy, cycle control, tolerability, and safety of this new monophasic COC (NOMAC $2.5 \mathrm{mg} / 17 \beta-\mathrm{E}_{2} 1.5 \mathrm{mg}$ ) compared to a COC containing drospirenone (DRSP) and EE. ${ }^{30,31}$ In a study conducted in the $\mathrm{US}^{30}$ and in several Latin American countries, 2,281 healthy women of 18-50 years of age were allocated in a ratio of $3: 1$ to NOMAC/17 $\beta-\mathrm{E}_{2}$ in a $24 / 4$ day regimen or to DRSP $3.0 \mathrm{mg} / \mathrm{EE} 30 \mu \mathrm{g}$ in a $21 / 7$ day regimen for 13 consecutive cycles. The Pearl Indices for the subset of women of 18 to 35 years of age were 1.3 (95\% CI: 0.66-2.2) and 1.9 (95\% CI: 0.69-4.11) in the study drug and comparator groups, respectively, and the 1-year cumulative pregnancy rates were 1.2 (95\% CI: 0.69-2.16) and 1.8 (95\% CI: 0.81-4.05), respectively. At the end of the year of observation, $32.9 \%$ of the women in the NOMAC/17 $\beta-\mathrm{E}_{2}$ group reported shorter, lighter bleeding or an absence of scheduled bleeding; however, unscheduled bleeding or spotting episodes were similar in both groups of users. With respect to side effects, the prevalence of acne decreased from $33 \%$ at the start of the study to $22 \%$ and $14 \%$ at the end of the year of use in the NOMAC and DRSP groups, respectively. The most common side effects with the new COC were acne (16.4\%), weight gain (9.5\%), and irregular withdrawal bleeding $(9.1 \%) .{ }^{30} \mathrm{~A}$ similar study was conducted in several European countries. ${ }^{31} \mathrm{~A}$ total of 1,591 women were randomized to an NOMAC/17ß-E $\mathrm{E}_{2} \mathrm{COC}$ and 535 to a DRSP/EE COC. 
Pearl Indices were 0.38 and 0.81 in the NOMAC/17 $\beta-\mathrm{E}_{2}$ and DRSP/EE groups, respectively, for women aged $\leq 35$ years and 0.31 and 0.66 , respectively, for the entire population of women (18-50 years) in the two groups. Bleeding patterns and the frequency of adverse events were similar to those found in the other RCT. ${ }^{31}$

VTE and pulmonary embolism are major concerns with the use of various different COCs and constitute wellestablished serious adverse events during the use of any COC, although they are more likely to occur in the first year of use. Nonetheless, no reports have yet been published on the prevalence of VTE with these new COCs. ${ }^{32}$ However, the controversy regarding VTE and the use of COCs containing EE and a new progestin remains an issue..$^{33,34}$ Many confounding factors such as obesity, a sedentary lifestyle, and smoking, among others, need to be taken into account. The introduction of new progestins and the use of low doses of estrogen and novel estrogens are strategies that may contribute toward reducing the incidence of VTE.

Another aspect of COC development is the use of estetrol, a natural estrogen produced in the fetal liver, which has a weaker effect than that of $E_{2}$. It is currently under investigation in a Phase II clinical trial of a new COC containing estetrol $20 \mathrm{mg}$ and desogestrel $150 \mathrm{mg} .{ }^{35}$ The information available so far shows anovulation, gonadotropin suppression, no increase in $\mathrm{E}_{2}$ levels, an acceptable bleeding pattern, and no significant increase in $\mathrm{SHBG}^{35}$

In addition, there are some new COC options in the pipeline that consist of variations to existing COCs and some of these pills may soon be available on the US market. One new COC is Quartette ${ }^{\mathrm{TM}}$ (Teva Pharmaceutical Industries Ltd., Petach Tikva, Israel), with a 91-day LNG/EE regimen; however, the estrogen dose increases at three different points over the first 84 days, while the amount of progestin remains consistent. This is followed by 7 days of $10 \mu \mathrm{g}$ of EE in an extended regimen $\mathrm{COC}$ designed to minimize episodes of unscheduled bleeding or breakthrough bleeding. In addition, Bayer has launched a new COC, Yaz Flex ${ }^{\circledR}$, in several countries. This COC is designed for use in an extended regimen of DRSP/EE $20 \mu \mathrm{g}$ with a flexible schedule that would allow users to decide if and when they want to have withdrawal bleeding, with options ranging from 25 to 120 days.

\section{Transdermal contraceptives}

\section{Transdermal patch}

The only transdermal contraceptive patch currently available on the market consists of a combination of $\mathrm{EE}$ and norelgestromin (Evra ${ }^{\circledR}$; Janssen Pharmaceuticals, Inc.,
Titusville, NJ, USA). ${ }^{36}$ Fluctuations in plasma levels are reported to be fewer with this patch than with COCs. Its main advantage lies in the fact that instead of daily pill intake, the patch requires to be changed only once a week, which may minimize problems with compliance and thus improve efficacy, ${ }^{37-40}$ although efficacy still remains similar to that found with COCs. ${ }^{41}$ Another advantage of this patch is that even after exposure to heat, humidity, and exercise, fewer than $5 \%$ had detached either fully or partially from the skin. ${ }^{40}$ Although its contraceptive efficacy has been described as being similar to that of COCs and the progestin-only pill, ${ }^{41}$ the EE serum levels found in patch users are higher than those found in users of COCs containing $30 \mu \mathrm{g}$ of EE and in users of the combined vaginal ring (CVR). This is one of the factors that explain the higher risk of VTE. ${ }^{42}$ Additionally, a higher failure rate was described among obese women, mainly those with weight over $90 \mathrm{~kg}$. ${ }^{43}$

Two new patches are under investigation or indeed, ready to be launched in some markets. One of these patches is currently being developed by Agile Therapeutics (Princeton, NJ, USA) and releases a low dose of LNG. It is intended predominantly for breastfeeding women or those with contraindications to contraceptives containing EE. This patch is designed to be replaced every 7 days and to be used in a continuous 28-day regimen with no patch-free interval. It has been tested at two doses: 1) 75 $\mu \mathrm{g} /$ day (AG1000-12.5); and 2) $\sim 40 \mu \mathrm{g} /$ day $(\mathrm{AG} 1000-6.5){ }^{44}$

The other patch undergoing development is produced by the same company and the approval is pending in the US and European countries. It releases EE and LNG (AG200-15, Twirla $^{\circledR}$ ) and is designed to be replaced every 7 days for 3 weeks, followed by a 7-day patch-free interval. It is round in shape and about 2.25 inches in diameter. The amount of EE is approximately equivalent to that of a $30 \mu \mathrm{g}$ COC and the dose of LNG $(\sim 100 \mu \mathrm{g})$ is similar to that found in COCs. One study compared this patch to a COC containing EE/LNG and showed that exposure to EE and LNG was lower with the patch than with the COC. ${ }^{44} \mathrm{~A}$ Phase II, threecycle study evaluated three patches containing different EE/ LNG doses in obese (body mass index $[\mathrm{BMI}] \geq 30$ ) and 75 nonobese (BMI <30) women. ${ }^{44}$ AG200-15 suppresses ovulation in obese and nonobese women; however, more in nonobese versus obese women. ${ }^{44}$

Another study conducted with 123 women evaluated patches with different doses of EE and a progestin, and reported a dose-dependent response with respect to ovulation control, cycle control, and tolerability. ${ }^{45,46}$ In women who had been using the method for periods of less than 18 months, the 
incidence of side effects was lower than that found with COCs and ovulation returned soon after discontinuation. ${ }^{45,46}$

In addition, three low-dose patches produced by Bayer are currently undergoing Phase III development. The size of the patches and the amount of steroids contained in them are different: the first measures $11 \mathrm{~cm}^{2}$ and contains $0.55 \mathrm{mg}$ EE/0.21 gestodene (GSD), while the second measures $7 \mathrm{~cm}^{2}$ and contains $0.35 \mathrm{mg} \mathrm{EE} / 0.67 \mathrm{GSD}$, and the third measures $5.5 \mathrm{~cm}^{2}$ in area and contains $0.275 \mathrm{mg} \mathrm{EE} / 1.05 \mathrm{mg}$ GSD. All require to be changed weekly and also entail a 7-day patchfree interval. Two studies conducted with 3,300 women in several countries are now complete. The effect on hemostasis and lipid and carbohydrate metabolism has been evaluated and a Phase II pharmacodynamics study has also been conducted. ${ }^{47}$ Another study assessed ovulation inhibition with a new, transparent patch with a total area of $10 \mathrm{~cm}^{2}$. This patch contained $0.9 \mathrm{mg}$ EE/1.9 $\mathrm{mg}$ GSD and was tested in 199 volunteers throughout two menstrual cycles. The main results showed ovulation inhibition in all volunteers, with suppression of the mid-cycle luteinizing hormone surge. In $85.7 \%$ of participants, ovulation returned in the first cycle following termination of treatment. ${ }^{48}$ No alterations were observed in prothrombin fragments $1+2$ or D-dimer when the patch was compared with a COC containing $0.03 \mathrm{mg}$ EE/0.15 mg LNG. ${ }^{49}$ An application has been made to the European authorities; however, there is no information on whether an application has been made in the US.

Another patch currently at Phase III of development releases norethindrone acetate and has been developed for use once a week with a 1-week patch-free interval. No data are as yet available. ${ }^{47}$

\section{Transdermal gel}

Nestorone (NES) is a 19-norprogesterone derivative that binds almost exclusively to the progesterone receptor without interfering with receptors for other steroids. ${ }^{50,51}$ It is inactive orally. NES has been reported to be the most effective of all the available progestins with respect to ovulation inhibition and to have no androgenic or estrogenic activity in vivo. ${ }^{51}$ Due to the elevated potency of this progestin, contraceptive efficacy is achieved at low doses when the drug is delivered via subdermal implants, vaginal rings, or transdermally. ${ }^{51}$ NES has been tested in a commercial gel at four different doses: $1.2 \mathrm{mg}, 2.3 \mathrm{mg}, 4.5 \mathrm{mg}$, and $9.0 \mathrm{mg} .{ }^{52}$ A single dose of the gel was administered to the periumbilical area of six volunteers, with the $2.3 \mathrm{mg}$ dose being repeated daily for 5 days. Serum levels of NES 24 hours after administration of the gel were adequate for therapeutic purposes, and the levels remained constant on the fifth day of use, suggesting that one single dose is probably sufficient. ${ }^{52}$

In addition, a gel containing $\mathrm{E}_{2}$ and NES is currently being developed. Studies have identified a combination dose that effectively delivers NES, while allowing regular bleeding patterns. So far, the drug has been well tolerated, with no serious adverse events and no skin irritation at the site of application. The Phase II study in which volunteers received three different doses of the product for 21 days with a washout period between doses is now complete, with the main results showing anovulation at all the doses used, with no serious adverse events or skin irritation..$^{45,46}$

\section{Transdermal spray}

A transdermal system, Metered Dose Transdermal System $^{\circledR}$ (Acrux Ltd, West Melbourne, Australia), was tested in Australia. This spray delivers drugs to the skin surface and with the aid of safe enhancers (ACROSS ${ }^{\circledR}$ Enhancers; Acrux Ltd) forms a reservoir within the skin from which the drug is slowly absorbed into the circulation over a period of many hours (Patchless Patch ${ }^{\mathrm{TM}}$ Delivery; Acrux Ltd). ${ }^{53}$ A Phase I pharmacokinetics study was conducted on Metered Dose Transdermal System delivery of NES to assess the effectiveness of a once-a-day NES delivery regimen in achieving serum levels capable of inducing anovulation. ${ }^{54}$ Peak NES concentration was achieved almost 20 hours after administration, plateauing after 4-5 days of daily spray application. The most common adverse events were bruising or pain at the site. Anovulation was achieved in at least $98 \%$ of subjects. The elimination half-life of 27 hours after application is consistent with skin retention over 24 hours. Despite the limitations of this pharmacokinetic trial, the results highlighted the potential of this new progestin and novel delivery system for contraception. A spray formulation incorporating both NES and an estrogen (EE or $\mathrm{E}_{2}$ ) is currently undergoing initial pharmacokinetic studies. ${ }^{54}$

\section{Vaginal ring}

There are only two vaginal rings currently available on the market. One is a CVR marketed as NuvaRing ${ }^{\circledR}$ (Merck). This ring releases $120 \mu \mathrm{g}$ of etonogestrel (ENG) and $15 \mu \mathrm{g}$ of $\mathrm{EE} /$ day and is approved for use over a 3-week period. The ring is then removed for 1 week, during which the user experiences uterine bleeding. Two studies described a continuous use regimen and confirmed the good acceptability and good cycle control associated with this method; however, it is currently off-label for that application. ${ }^{55,56}$ Reports have suggested that the main reason for women to switch from other contraceptive 
methods to the CVR (47\%) is because they view it as an attractive contraceptive method. ${ }^{57}$ In fact, over $90 \%$ of users report being satisfied with the ring. ${ }^{57}$ Nevertheless, despite the low pregnancy rate reported, ${ }^{58}$ and although tolerability is equivalent to that of COCs and adverse events are few, the continuation rate with the CVR is similar or even lower than that of COCs. Six months after initiation, continuation rates as low as $26 \%$ have been reported for users of the CVR compared to $29 \%$ for the COC. ${ }^{59}$ The use of a vaginal ring or transdermal patch offers a potential advantage over COCs because it could improve user compliance. In a Cochrane Review it was observed that contraceptive effectiveness was similar for the patch or vaginal ring versus the COC. ${ }^{60}$ Also, patch users showed better compliance than COC users in three trials and in four trials it was observed that vaginal ring users showed more noncompliance than COC users. ${ }^{60}$

The other vaginal ring available on the market is a P-releasing vaginal ring (10 mg/day) designed for use by breastfeeding women (Progering ${ }^{\circledR}$; Laboratorios Andromaco, Santiago, Chile). This ring was developed by the Population Council, New York, NY, USA and has already been approved in Chile, Peru, Bolivia, the Dominican Republic, Ecuador, Guatemala, and Panama. Its external diameter is $58 \mathrm{~mm}$, with a radius of $8.4 \mathrm{~mm}$. It is made of a homogeneous mixture of soft, flexible silicone elastomers and micronized P. It releases approximately $10 \mathrm{mg}$ of $\mathrm{P}$ per day in vitro for an effective life span of 3 months. P offers certain advantages to lactating women who need contraception, since it is a natural hormone and unlikely to affect the infant. In addition, it may prolong lactational amenorrhea and the reduction in bleeding may improve anemia, a condition that affects millions of women in developing countries. ${ }^{61}$ High levels of $\mathrm{P}$ are achieved after the first week of use $(33.7 \mathrm{nmol} / \mathrm{L})$, decreasing to $50 \%$ of this level at 9 weeks and $30 \%$ at 16 weeks of use. ${ }^{62}$ In a large trial with lactating women using the 10-mg/day P-only ring, the pregnancy rate at the end of 1 year was $1.5 / 100$ women $^{63}$ and $46 \%$ of the continuers remained in amenorrhea. Another study assessed extended use of the ring in 192 users for 4 months (instead of 3 months), concluding that it was safe and effective as a contraceptive for nursing women over this period of time. ${ }^{64}$ Further studies are currently being conducted in 20 centers in India. ${ }^{65}$

During the initial development of this vaginal ring, a model containing NES alone was tested at three different doses: 50, 75, and $100 \mu \mathrm{g} /$ day. ${ }^{66}$ After an initial peak, NES serum levels remained constant at around 125, 200, and $250 \mathrm{pmol} / \mathrm{L}$, respectively, and luteal activity was rare (1.2\%-2.6\% of samples at any given period). It was concluded that a vaginal ring delivering either 50 or $75 \mu \mathrm{g}$ of NES per day would result in appropriate anovulation rates. However, irregular bleeding patterns were a common consequence and development was suspended. Nevertheless, a vaginal ring providing higher doses of NES may improve cycle control, and ring prototypes with a low dose of $\mathrm{E}_{2}$ as a backup are currently being tested. ${ }^{67}$

Following on that study, the Population Council developed a new CVR containing NES and $\mathrm{EE}^{68}$ that was tested at three different dose combinations. The mean in vitro drug release rates for the three doses were 150 and 15, 150 and 20, and 200 and $15 \mu \mathrm{g} /$ day of NES and EE, respectively, with luteal activity being observed in $17 \%, 7 \%$, and $12 \%$ of the women, respectively. Based on that study, the ring releasing $150 \mu \mathrm{g} /$ day NES and $15 \mu \mathrm{g} /$ day EE, the lowest effective dose of both steroids, was selected for further development.

The Population Council has now completed studies on the new CVR that releases NES $150 \mu \mathrm{g} /$ day and EE $15 \mu \mathrm{g} /$ day. ${ }^{69}$ NES is a potent non-androgenic $\mathrm{P}$ derivative that has not been used in any other contraceptive method. The ring is a donut-shaped, silicone elastomer ring with a two-channel core containing the steroids, one channel releasing NES alone and the other channel releasing both NES and EE. ${ }^{69}$ Fewer bleeding problems were found with this combination and dose when compared to another CVR. One of the main differences with the NuvaRing is that this new CVR is designed to last for 1 year (13 cycles), thus avoiding the need to resupply. Another advantage is its affordable cost, which is an important factor, particularly in developing countries. It is designed to be used for 21 days, followed by a 1-week, ring-free interval.

Two reports described data from 2,277 CVR users at 27 centers in Australia, Europe, Latin America, and the US. $^{70,71}$ The overall continuation rates were around $60 \%$ and there were no regional differences. Contraceptive efficacy was comparable to that found with other contraceptive methods. In addition, bleeding control was excellent, and the return to fertility following discontinuation was fast. No changes in weight, blood pressure, or hemoglobin levels were observed. The factors associated with early discontinuation were, being able to feel the ring in place, and difficulty in remembering to reinsert the ring on schedule. In addition to the studies on safety and efficacy, three sub-studies were conducted to assess the impact of this CVR on liver proteins, vaginal microflora and CVR flora, and on endometrial histology. ${ }^{72}$

Another CVR containing NES and $\mathrm{E}_{2}$ will be evaluated in the Contraceptive Clinical Trials Network of the National Institute of Child Health and Human Development (NICHD). ${ }^{73}$ 
The investigators will conduct a double-blind, dose-finding, $\mathrm{RCT}$, the main objective of which is to evaluate the effect of three different doses of an $\mathrm{NES} / \mathrm{E}_{2}$ CVR on cycle control, ovulation inhibition, and pharmacokinetics. Each CVR is designed for 3 months' continuous use and each subject will be requested to use two rings consecutively over a 6-month study period. ${ }^{73}$

The Population Council, in collaboration with the NICHD and HRA Pharma (Paris, France), is currently developing a 3-month vaginal ring containing the selective $P$ receptor modulator, ulipristal acetate (UPA). ${ }^{45,46}$ UPA is a 19-norprogesterone derivative with agonist and antagonist effects. Primary results showed ovulation inhibition in $68 \%$ of the cycles evaluated, with UPA levels above 6-7 ng/mL. ${ }^{45,46,74}$ Further studies are needed to establish the optimal dose to ensure high anovulation rates. A major limitation to the long-term use of UPA is the development of endometrial thickening, which, although benign, may represent a cause for concern. ${ }^{45,46,74}$

\section{Once a month combined injectable contraceptives}

Although two combined injectable contraceptives (CIC) are already available on the market in many countries, many women around the world do not have access to these effective and convenient contraceptives. One of these CIC consists of a combination of $25 \mathrm{mg}$ of medroxyprogesterone acetate and $5 \mathrm{mg}$ of estradiol cypionate, a long-acting $\mathrm{E}_{2}$ ester. This contraceptive was marketed in the US for only 2 years under the brand name Lunelle ${ }^{\circledR}$ and in many countries it is known as Cyclofem ${ }^{\circledR} /$ Cyclofemina. $^{75}$ The Concept Foundation maintains the rights to this CIC and has licensed Sun Pharmaceutical Industries Ltd. (Mumbai, India) to manufacture and market Cyclofem ${ }^{\circledR}$ in the developing world and to bring this product back onto the US market.

\section{Progestin-only contraceptives}

\section{Intrauterine contraceptives}

One of the most common progestin-only contraceptives is the LNG-releasing intrauterine system (LNG-IUS), which releases $20 \mu \mathrm{g}$ of LNG daily and has been on the market worldwide for more than 10 years. It is approved principally for contraception, the treatment of HMB, and in some countries as endometrial protection during estrogen therapy in postmenopausal women. ${ }^{76,77}$ Introduction of the LNG-IUS onto the market many years ago was responsible for a tremendous increase in the use of intrauterine contraceptives, particularly in countries such as the USA, where intrauterine contraceptive use was almost nonexistent. The contraceptive performance of the LNG-IUS is high, similar to that of tubal ligation, ${ }^{7}$ and there are few adverse effects. Furthermore, the LNG-IUS offers certain non-contraceptive benefits. ${ }^{78}$ However, despite these advantages, many physicians still refuse to insert this system in nulligravidas because they consider it to be a painful or difficult procedure. In addition, the fact that the LNG-IUS offers protection for up to 5 years may represent a barrier to women who want contraception for shorter periods of time.

Recently, the same pharmaceutical company (Bayer) launched a new LNG-IUS system in several countries. This new LNG-IUS releases $12 \mu \mathrm{g}$ of LNG daily and has been given the brand name of Jaydess ${ }^{\circledR}$ or Skyla ${ }^{\circledR}$. The LNG-IUS currently on the market (Mirena ${ }^{\circledR}$; Bayer Oy, Turku, Finland) measures $32 \mathrm{~mm} \times 32 \mathrm{~mm}$; however, this new LNG-IUS is smaller in both length and width $(28 \mathrm{~mm} \times 28 \mathrm{~mm})$ and the diameter of the insertion tube for the new LNG-IUS is $3.80 \mathrm{~mm}$ compared to $4.75 \mathrm{~mm}$ for the Mirena inserter. In addition, the new device has a silver ring at the top, which makes it easier to visualize at ultrasound. Evaluation of the performance of the new LNG-IUS showed a Pearl Index (95\% CI) of $0.17(0.0-0.93)$ compared to $0.0(0.0-0.59)$ for the Mirena. The cumulative 3-year pregnancy rates, according to the Kaplan-Meier analysis, were 0.005 and 0.000 for Jaydess/Skyla and Mirena, respectively. The expulsion rate was lower with the new device: $1 / 239(0.4 \%)$ compared to $4 / 256(1.6 \%)$. However, despite the fact that there were fewer bleeding/spotting days with Jaydess/Skyla, there were no significant differences between the two devices in this respect. Amenorrhea increased from $2.7 \%$ and $5.9 \%$ in the second 90 -day reference period to $12.7 \%$ and $23.6 \%$ in the final 90-day reference period for the new LNG-IUS and Mirena groups, respectively. ${ }^{79}$ Acceptance of the new device appears to be high in the markets in which it has already been launched and many physicians prefer this new device for nulligravidas despite the fact that ease of insertion has been shown to be similar to that found with Mirena. ${ }^{80}$

Another LNG-IUS developed by the same company (Bayer) has already undergone testing. This device releases $16 \mu \mathrm{g}$ of LNG daily and is designed for up to 5 years' use. However, despite the fact that the results have already been published, ${ }^{79}$ no information is yet available on its registration in any country. Additionally, Uteron Pharma Operations (Leige, Belgium) has developed a new LNGIUS (Levoser ${ }^{\circledR}$ ) that is similar to Mirena and also releases $20 \mu \mathrm{g}$ of LNG daily. This device has been approved for up to 4 years of use and its introduction process has been 
initiated in some European countries for the treatment of HMB. ${ }^{81}$

Another product under development and currently undergoing evaluation is an IUS that releases an SPRM, UPA, a tissue-selective $P$ agonist and antagonist. ${ }^{82,83}$ UPA has been approved in Europe and in the USA as an emergency contraceptive; however, it could potentially be developed as a female contraceptive. ${ }^{84-86}$ One experimental study conducted in rhesus monkeys ${ }^{87}$ evaluated UPA in an IUS to assess its ability to suppress endometrial growth and induce amenorrhea. The IUS was inserted in ovariectomized monkeys previously treated with $\mathrm{E}_{2}$ and $\mathrm{P}$ to create artificial menstrual cycles. Following uterine bleeding, the UPA-releasing IUS (at doses of $20 \mu \mathrm{g} /$ day or $40 \mu \mathrm{g} /$ day) or empty tubes were inserted. After 3.5 cycles, the uteri were removed.

During that study, the animals that received the empty IUS had a mean of $11.7 \pm 0.9$ bleeding days compared to $1.0 \pm 0.45$ in the animals that received a UPA-IUS $(P<0.05) .{ }^{88}$ In addition, in the animals treated with a UPA-IUS, the endometrium was thinner; however, in some animals, a large, dilated endometrial pattern was found, resembling cysts. These results indicate that a UPA-IUS may represent a useful addition to the range of contraceptive methods available and for inducing amenorrhea. ${ }^{88}$

\section{Contraceptive subdermal implants}

The two subdermal contraceptive implants available on the market are the two-rod, LNG-releasing implant system (Jadelle $^{\circledR}$; Bayer) and an ENG-releasing single implant (Implanon ${ }^{\circledR}$; Merck). Contraceptive efficacy is high with both implants, side effects are few and continuation rates are good. ${ }^{89}$ Nevertheless, the main reason for discontinuation is bleeding abnormalities. ${ }^{90}$ Another LNG-releasing implant, Sino-implant (II), manufactured in the People's Republic of China by Shanghai Dahua Pharmaceuticals Co, Ltd., (Shanghai, People's Republic of China) has been launched in 20 developing countries and is deemed to be in compliance with the World Health Organization's Good Manufacturing Practices.

Merck recently introduced a new generation ENGreleasing implant called Nexplanon ${ }^{\mathrm{TM}}$, which has already been launched in several countries. Essentially, the insertion system was significantly improved in the new implant to ensure correct insertion and minimize the risk of misplacement, which could result in difficulties at removal. Additionally, $15 \mathrm{mg}$ of barium sulfate were added to the core of the Nexplanon, meaning that it is detectable by X-ray. This will ensure that the device can be detected when inserted deep in the arm or in the case of women whose weight may have increased significantly, situations that could create problems for health care professionals regarding how to remove the device.

In addition, the Population Council has developed an NES-releasing implant. The results from the first study ${ }^{91}$ showed peak NES levels of up to $10.1 \mathrm{ng} / \mathrm{mL}$ after insertion of the capsule, while serum $\mathrm{E}_{2}$ levels were maintained below $100 \mathrm{pg} / \mathrm{mL}$, indicating anovulation. In a trial ${ }^{92}$ involving 1,570 women-months of exposure, no pregnancies occurred. Plasma NES levels declined by around $50 \%$ between the first and the twenty-fourth months of use; however, ovulation remained suppressed. No changes were found in lipoproteins or in any of the other clinical chemistry parameters.

A 2-year trial of a single NES rod was conducted, involving a total of 300 women at three Latin American clinics. ${ }^{93}$ Three unexpected pregnancies occurred at 18,21, and 24 months of exposure and the trial was halted. Nevertheless, the cumulative life-table pregnancy rate was $1.7 / 100$ women at 2 years, with a Pearl Index of 0.6 per 100 women-years of use, a rate that could be considered acceptable. There is no plan to continue developing this implant because to do so the Population Council would have to conduct a large Phase III clinical trial (R Sitruk-Ware, Population Council, personal communication, February, 2013).

\section{Emergency contraception}

Emergency contraception (EC) is available worldwide, with LNG EC pills being available over-the-counter in around 70 countries. ${ }^{94}$ The first EC method to be made available was the Yuzpe method, which consists of two COC pills containing EE $100 \mu \mathrm{g} / \mathrm{LNG} 0.5 \mathrm{mg}$, to be taken 12 hours apart. ${ }^{95}$ This method was not, however, marketed specifically as an EC and was quickly substituted by a regimen consisting of two doses of $0.75 \mathrm{mg}$ LNG alone, taken 12 hours apart and then, more recently, by one $1.5 \mathrm{mg}$ dose of LNG taken as soon as possible and within 72 hours of unprotected intercourse. ${ }^{96,97}$ This formulation has now been introduced onto the market in many countries as a product specifically marketed as an EC. Another product that can be used as an EC is the copper intrauterine device when inserted within the first 5 days after unprotected intercourse. The copper intrauterine device is highly effective as an EC, with the advantage that protection is then maintained for up to 10 years after insertion. ${ }^{98}$

Over the past few years, a new EC pill has been introduced onto the market in several European countries, in the US and, more recently, in some Latin American countries. This pill 
contains $30 \mathrm{mg}$ of UPA, which is a 19-norprogesterone derivative (17 alpha-acetoxy-11-[4-N,N-dimethylaminophenyl]19-norpregna-4,9-diene-3,20-dione) selective $\mathrm{P}$ receptor modulator. The efficacy of this new EC pill (EllaOne ${ }^{\circledR} /$ Ella $^{\circledR}$; HRA Pharma) has been found to be similar to that of LNG when used within 72 hours of unprotected sexual intercourse. ${ }^{99}$ However, it has also been tested up to 120 hours after unprotected intercourse. ${ }^{100,101}$ Pregnancy rates were evaluated in women who received UPA or LNG and took the medication within 72 hours or within 120 hours following intercourse. Of the 50 pregnancies that occurred during this study, 20 occurred in the UPA group and 30 in the LNG group. The pregnancy rate in the users of these compounds was significantly lower than the expected pregnancy rate ( $1.8 \%$ observed versus $5.5 \%$ expected for UPA, $P=0.001$, and $2.6 \%$ observed versus $5.4 \%$ expected for $\mathrm{LNG}, P=0.001$ ). In addition, in the women who used EC between 72 and 120 hours after intercourse (UPA, n=97; LNG, n=106), three pregnancies occurred, all in LNG users (odds ratio [OR]: 0.57; 95\% CI: 0.29-1.09). ${ }^{100,101}$ The most common adverse event was headache (19\%) in both groups. Onset of the next menstrual period following EC use was later than expected in the UPA users and earlier than expected in the LNG users $(P=0.001)$. Although the power of the study was insufficient to enable the superiority of UPA to be confirmed, the results indicate that UPA is better than LNG when taken as EC within 120 hours of intercourse (OR: 0.55; 95\% CI: 0.32-0.93). With respect to the mechanism of action of UPA, it has been well established that, when the drug is administered before the beginning of the luteinizing hormone (LH) surge or after the onset but before the LH peak, it inhibits follicle rupture within 5 days. However, it has to be taken into account that ovulation cannot be avoided completely and follicular rupture may occur later. For this reason, women need to be advised to use protection during any consequent sexual intercourse. ${ }^{102}$

It has recently been reported that non-steroidal antiinflammatory drugs are able to inhibit follicular rupture and can be used as EC or can be added to LNG as EC to increase the effectiveness of the method. ${ }^{103,104}$ Activation of the cyclooxygenase-2 (COX-2) enzyme affects prostaglandin production during follicular development and ovulation, and its role is important, principally at the follicular rupture stage. ${ }^{105}$

The selective COX-2 inhibitor meloxicam was administered orally ${ }^{106}$ (15 mg versus $30 \mathrm{mg}$ ) to evaluate whether the drug interferes with the ovulatory process when given for 5 days, beginning after the leading follicle has reached $18 \mathrm{~mm}$ in size. At the $15 \mathrm{mg} /$ day dose, ovulation occurred in $50 \%$ of cases, while at the $30 \mathrm{mg}$ dose, ovulation occurred in $9 \%$ of the cycles $(P=0.006)$. Ovulatory dysfunction was found in $45.5 \%$ and $27 \%$ of cycles with the $30 \mathrm{mg} /$ day and $15 \mathrm{mg}$ /day doses, respectively. Similar results were found with the two doses when administered for 6 days. The most common adverse events were low abdominal pain, bloating, and hot flushes. The main advantage is that COX-2 inhibitors do not interfere with ovarian steroids or with the length of the menstrual cycle. Other investigators ${ }^{107}$ evaluated the use of a specific prostaglandin endoperoxide-2 inhibitor (celecoxib, $400 \mathrm{mg}$, orally). Those authors concluded that although Celecoxib provokes ovulatory dysfunction when administered either before or after the LH surge, many of the women in the trial ovulated normally; therefore, the usefulness of this selective COX-2 inhibitor as an EC is limited. ${ }^{108}$

\section{Contraceptives with additional benefits}

Dual-protection contraceptive methods are currently being developed by several organizations. One such method consists of a vaginal ring that delivers LNG in addition to antiretrovirals such as tenofovir (developed by CONRAD, Arlington, VA, USA), dapivirine (developed by the International Partnership for Microbicides, Silver Spring, MD, USA), and MIV-150 (developed by the Population Council, New York, NY, USA). ${ }^{54}$ Any method that combines contraception with human immunodeficiency virus (HIV) protection is welcome and may fill an important gap. Some studies are currently being conducted with C31G Glyminox 1\% gel (Savvy), a vaginal microbicide and contraceptive (Biosyn, Inc.; Adamis Pharmaceuticals Corporation, San Diego, CA, USA). This is a vaginal gel that is designed for use 15 minutes prior to sexual intercourse. Other formulations currently being tested include one that can be inserted 24 hours prior to intercourse. This gel is also being tested as a microbicide for the prevention of HIV transmission. ${ }^{45,46}$

Another possibility that is currently undergoing evaluation is a non-contraceptive vaginal microbicide, carrageenan, PDR98-15. It belongs to the sulfated polysaccharide class of compounds and has been shown to exert an antiviral and antibacterial effect against HIV, herpes simplex virus type 2, and Neisseria gonorrhoeae (Carraguard ${ }^{\circledR}$ [CARRA]; The Population Council, New York, NY, USA) ${ }^{109-113}$ This gel is being tested as a vehicle for the vaginal delivery of LNG as a contraceptive and to prevent sexually transmitted infections. CARRA/LNG could be used "on demand" and applied prior to intercourse, which may be an attractive alternative for many women/couples who have sexual intercourse only sporadically. 
Results from those studies ${ }^{110}$ confirmed good maximum serum LNG levels at 6 and 12 hours following administration. In addition, ${ }^{114}$ when women with ovarian follicles of $12-14 \mathrm{~mm}, 15-17 \mathrm{~mm}$, or $\geq 18 \mathrm{~mm}$ in diameter used either CARRA/LNG or CARRA gel alone, no follicular rupture occurred in the 5-day period following administration in $74 \%$ of the CARRA/LNG treatment cycles and in $30 \%$ of the CARRA gel cycles. Sexual intercourse did not interfere with the absorption rate of the gel. ${ }^{115}$

\section{Contraception "on demand"}

Many women/couples have sexual intercourse only occasionally and for this reason want contraceptives that can be used only on the days on which they have sex. To meet this demand, several studies are being conducted to establish the usefulness of LNG as a pericoital form of EC. The woman would have the option of taking the pill either before or after sexual intercourse and would be able to use it more than once a month, if necessary. A study conducted in Brazil and in the US enrolled women who expected to have sex only 1-4 days a month for 6.5 months. ${ }^{116}$ These women took one tablet of LNG $0.75 \mathrm{mg}$ within the 24-hour period either preceding or following sex; however, no more than one dose could be taken in any 24-hour period. The Pearl Index was 22.4 (95\% CI: 4.6-65.4), higher than expected, probably as a result of the small sample size. Currently, the World Health Organization is conducting a similar trial with a larger sample of women and the inclusion criteria have been changed to include women who have sex for up to 6 days a month.

\section{Comments and conclusion}

New contraceptive methods currently being developed include: 1) contraceptives containing new natural estrogens and novel progestins; 2) new drugs with different mechanisms of action from the existing ones that act directly on follicular development and disrupt the ovulation process; 3 ) methods with a similar delivery system to existing methods but using new drugs; 4) methods with a new delivery system; 5) contraception with non-contraceptive benefits; and 6) contraception "on demand". Nevertheless, even today, most of the contraceptives available on the market and those currently undergoing research and development interfere with ovulation or follicular development and also affect the woman's steroid production. However, research conducted over the past few decades has provided more information on gamete physiology and interaction, offering new opportunities for the development of novel contraceptives that could act by interfering with the process of gamete interaction or with the chemoattraction or chemorepulsion of spermatozoa to the fertilization site. Additionally, there are many progestinonly contraceptives on the market that are highly effective, with efficacy rates that are similar to those found with female sterilization, ${ }^{7}$ good acceptance, and low discontinuation rates. Nevertheless, the main problem with this type of contraception is unexpected uterine bleeding, which could result in premature discontinuation, since this complaint often constitutes a concern and a cause of dissatisfaction for many women. ${ }^{117}$ For this reason, it is imperative that existing methods be improved and new ones developed.

The development of contraceptive methods presents a challenge to researchers and to pharmaceutical companies. When treating any disease, the drug in use may fail and the health care professional may have to substitute it at any time. However, with contraceptives the situation is different because failure can result in pregnancy, and generally speaking, that pregnancy would be unplanned. Unplanned pregnancy may, in turn, lead to abortion, a procedure that can be unsafe in many settings and may have severe consequences. Another problem when evaluating new contraceptives is that anovulation is a surrogate marker ${ }^{118}$ and is not appropriate for evaluating contraceptive methods. Clinical trials investigating a contraceptive method have to be conducted with women who are exposed to the risk of pregnancy.

In addition, during the development of new contraceptives, the investigators and the pharmaceutical companies need to take different cultural behaviors into account. The best contraceptive is one that fulfills women's needs, with acceptable side effects and at an affordable price in different settings. It is no longer acceptable that many excellent contraceptives remain unavailable to millions of women/couples because the cost is unaffordable in some settings. Local culture is an important issue that in some cases may constitute a barrier to use, as does the opposition of some religious leaders.

Many articles have reported that around $50 \%$ of pregnancies are unintended, irrespective of the woman's social class, age, marital status, ethnicity, or whether the woman lives in a developed or developing country. However, unplanned pregnancy is more common in the poorer socioeconomic strata and in developing countries. ${ }^{119-122}$ Still, the development of new contraceptives is a challenge and a high-cost process bearing in mind that the regulatory authorities require almost 3,000 women to be enrolled in trials and thousands of months of exposure to be recorded.

The research and development of new effective, affordable contraceptives with few side effects is currently a subject of debate; however, new knowledge on the physiology 
of reproduction may improve this situation. Nevertheless, it is important for women to have access to contraception, for them to be able to use the method correctly, and for new contraceptive methods to also offer non-contraceptive benefits, an advantage that many health care professionals and women are now requesting. Many women want a contraceptive method that will enable them to schedule their bleeding or allow them to be in amenorrhea. Other women would like methods to ameliorate premenstrual symptoms, methods that can be used during breastfeeding, or methods that could be used "on demand" for women who have intercourse only occasionally. However, even today, millions of women/couples still have no access to contraceptive methods. This includes the longacting reversible contraceptives that have been shown to be safe, affordable, and effective, with pregnancy rates similar to those found with female sterilization. ${ }^{7}$ Advantage should be taken of the enormous amount of knowledge on gametes and gamete interaction obtained over three decades of in vitro fertilization for contraceptive development.

\section{Disclosure}

Luis Bahamondes has occasionally served on the Board of Merck Sharp \& Dohme and Bayer. The authors report no other conflicts of interest in this work.

\section{References}

1. World Health Organization. Medical Eligibility Criteria for Contraceptive use. 3rd ed. Geneva: World Health Organization; 2004.

2. Chang MC. Development of the oral contraceptives. Am J Obstet Gynecol. 1978;132(2):217-219.

3. Darroch JE, Singh S. Trends in contraceptive need and use in developing countries in 2003, 2008, and 2012: an analysis of national surveys. Lancet. 2013;381(9879):1756-1762.

4. Millennium Development Goals [webpage on the Internet]. United Nations; 2014. Available from: http://www.un.org/millenniumgoals/. Accessed September 15, 2013.

5. Temkin O. Soranus' Gynecology. Baltimore: The Johns Hopkins University Press; 1991.

6. Population Reference Bureau Staff. Transitions in world population. Popul Bull. 2004;59(1):1-43.

7. Winner B, Peipert JF, Zhao Q, et al. Effectiveness of long-acting reversible contraception. N Engl J Med. 2012;366(21):1998-2007.

8. Merkatz RB, Tokay B, Sitruk-Ware RL. Methods for female contraception: a model for innovation in drug delivery systems. Clin Pharmacol Ther. 2009;85(5):553-557.

9. Hugon-Rodin J, Chabbert-Buffet N, Bouchard P. The future of women's contraception: stakes and modalities. Ann N Y Acad Sci. 2010;1205: 230-239.

10. Zeun S, Uddin A, Zeiler B, Morrison D, Blode H. Pharmacokinetics of an oral contraceptive containing oestradiol valerate and dienogest. Eur J Contracept Reprod Health Care. 2009;14(3):221-232.

11. Astedt B, Jeppsson S, Liedholm P, et al. Clinical trial of a new oral contraceptive pill containing the natural oestrogen 17 beta-oestradiol. Br J Obstet Gynaecol. 1979;86(9):732-736.

12. Hoffmann H, Moore C, Kovacs L, et al. Alternatives of the replacement of ethinylestradiol by natural 17beta-estradiol in dienogest-containing oral contraceptives. Drugs Today (Barc). 1999;35(Suppl C):105-113.
13. Kivinen S, Saure A. Efficacy and tolerability of a combined oral contraceptive containing 17 beta-estradiol and desogestrel. Eur J Contracept Reprod Health Care. 1996;1:183.

14. Huber J, Foidart JM, Wuttke W, et al. Efficacy and tolerability of a monophasic oral contraceptive containing ethinylestradiol and drospirenone. Eur J Contracept Reprod Health Care. 2000;5(1): 25-34.

15. Spona J, Feichtinger W, Kindermann C, et al. Modulation of ovarian function by an oral contraceptive containing 30 micrograms ethinylestradiol in combination with $2.00 \mathrm{mg}$ dienogest. Contraception. 1997;56(3):185-191.

16. Bannemerschult R, Hanker JP, Wünsch C, Fox P, Albring M, Brill K. A multicenter, uncontrolled clinical investigation of the contraceptive efficacy, cycle control, and safety of a new low dose oral contraceptive containing 20 micrograms ethinyl estradiol and 100 micrograms levonorgestrel over six treatment cycles. Contraception. 1997;56(5): 285-290.

17. Endrikat J, Jaques MA, Mayerhofer M, Pelissier C, Müller U, Düsterberg B. A twelve-month comparative clinical investigation of two low-dose oral contraceptives containing 20 micrograms ethinylestradiol/75 micrograms gestodene and 20 micrograms ethinylestradiol/150 micrograms desogestrel, with respect to efficacy, cycle control and tolerance. Contraception. 1995;52(4): 229-235.

18. Piaggio G, von Hertzen H, Grimes DA, Van Look PF. Timing of emergency contraception with levonorgestrel or the Yuzpe regimen. Task Force on Postovulatory Methods of Fertility Regulation. Lancet. 1999;353(9154):721.

19. Düsterberg B, Nishino Y. Pharmacokinetic and pharmacological features of oestradiol valerate. Maturitas. 1982;4(4):315-324.

20. Zeun S, Lu M, Uddin A, Zeiler B, Morrison D, Blode H. Pharmacokinetics of an oral contraceptive containing oestradiol valerate and dienogest. Eur J Contracept Reprod Health Care. 2009;14(3):221-232.

21. Oettel M, Breitbarth H, Elger W, et al. The pharmacological profile of dienogest. Eur J Contracept Reprod Health Care. 1999;4(Suppl 1): $2-13$.

22. Mueck AO, Seeger H, Bühling KJ. Why use of dienogest for the first contraceptive pill with estradiol? Gynecol Endocrinol. 2010;26(2): 109-113.

23. Ben-Rafael Z, Mastroianni L Jr, Meloni F, Lee MS, Flickinger GL. Total estradiol, free estradiol, sex hormone-binding globulin, and the fraction of estradiol bound to sex hormone-binding globulin in human follicular fluid. J Clin Endocrinol Metab. 1986;63(5): $1106-1111$.

24. Endrikat J, Parke S, Trummer D, Schmidt W, Duijkers I, Klipping C. Ovulation inhibition with four variations of a four-phasic estradiol valerate/dienogest combined oral contraceptive: results of two prospective, randomized, open-label studies. Contraception. 2008;78(3): 218-225.

25. Palacios S, Wildt L, Parke S, Machlitt A, Römer T, Bitzer J. Efficacy and safety of a novel oral contraceptive based on oestradiol (oestradiol valerate/dienogest): a Phase III trial. Eur J Obstet Gynecol Reprod Biol. 2010;149(1):57-62.

26. Ahrendt HJ, Makalová D, Parke S, Mellinger U, Mansour D. Bleeding pattern and cycle control with an estradiol-based oral contraceptive: a seven-cycle, randomized comparative trial of estradiol valerate/ dienogest and ethinyl estradiol/levonorgestrel. Contraception. 2009;80(5):436-444.

27. Junge W, Mellinger U, Parke S, Serrani M. Metabolic and haemostatic effects of estradiol valerate/dienogest, a novel oral contraceptive: a randomized, open-label, single-centre study. Clin Drug Investig. 2011;31(8):573-584.

28. Fraser IS, Zeun S, Machlitt A, Mellinger U. A novel oral contraceptive comprising estradiol valerate/dienogest for the treatment of heavy and/or prolonged menstrual bleeding without organic cause: a double-blind, randomised, placebo-controlled trial. Int $J$ Gynecol Obstet. 2009;107(Supp1 2):S183-S184. 
29. Jensen J, Machlitt A, Mellinger U, Schaefers M, Fraser IS. A multicenter, double-blind, randomized, placebo-controlled study of oral estradiol valerate/dienogest for the treatment of heavy and/or prolonged menstrual bleeding. Fertil Steril. 2009;92(3):S32.

30. Westhoff C, Kaunitz AM, Korver T, et al. Efficacy, safety, and tolerability of a monophasic oral contraceptive containing nomegestrol acetate and 17ß-estradiol: a randomized controlled trial. Obstet Gynecol. 2012;119(5):989-999.

31. Mansour D, Verhoeven C, Sommer W, et al. Efficacy and tolerability of a monophasic combined oral contraceptive containing nomegestrol acetate and $17 \beta$-oestradiol in a 24/4 regimen, in comparison to an oral contraceptive containing ethinylestradiol and drospirenone in a 21/7 regimen. Eur J Contracept Reprod Health Care. 2011;16(6):430-443.

32. Dinger J, Assmann A, Möhner S, Minh TD. Risk of venous thromboembolism and the use of dienogest- and drospirenone-containing oral contraceptives: results from a German case-control study. J Fam Plann Reprod Health Care. 2010;36(3):123-129.

33. Lidegaard O, Nielsen LH, Skovlund CW, Løkkegaard E. Venous thrombosis in users of non-oral hormonal contraception: follow-up study, Denmark 2001-2010. BMJ. 2012;344:e2990.

34. Bitzer J, Amy JJ, Beerthuizen R, et al. Statement on combined hormonal contraceptives containing third- or fourth-generation progestogens or cyproterone acetate, and the associated risk of thromboembolism. Eur J Contracept Reprod Health Care. 2013;18(3):143-147.

35. Coelingh Bennink HJ, Skouby S, Bouchard P, Holinka CF. Ovulation inhibition by estetrol in an in vivo model. Contraception. 2008;77(3): 186-190.

36. Urdl W, Apter D, Alperstein A, et al; ORTHO EVRA/EVRA 003 Study Group. Contraceptive efficacy, compliance and beyond: factors related to satisfaction with once-weekly transdermal compared with oral contraception. Eur J Obstet Gynecol Reprod Biol. 2005;121(2): 202-210.

37. Abrams LS, Skee DM, Natarajan J, Wong FA, Anderson GD. Pharmacokinetics of a contraceptive patch (Evra/Ortho Evra) containing norelgestromin and ethinyloestradiol at four application sites. $\mathrm{Br} J$ Clin Pharmacol. 2002;53(2):141-146.

38. Abrams LS, Skee DM, Natarajan J, Wong FA, Lasseter KC. Multiple-dose pharmacokinetics of a contraceptive patch in healthy women participants. Contraception. 2001;64(5):287-294.

39. Abrams LS, Skee DM, Natarajan J, et al. Pharmacokinetics of norelgestromin and ethinyl estradiol delivered by a contraceptive patch (Ortho Evra/Evra) under conditions of heat, humidity, and exercise. J Clin Pharmacol. 2001;41(12):1301-1309.

40. Sicat BL. Ortho Evra, a new contraceptive patch. Pharmacotherapy. 2003;23(4):472-480.

41. Audet MC, Moreau M, Koltun WD, et al; ORTHO EVRA/EVRA 004 Study Group. Evaluation of contraceptive efficacy and cycle control of a transdermal contraceptive patch vs an oral contraceptive: a randomized controlled trial. JAMA. 2001;285(18):2347-2354.

42. Jick SS, Hagberg KW, Kaye JA. ORTHO EVRA and venous thromboembolism: an update. Contraception. 2010;81(5):452-453.

43. Zieman M, Guillebaud J, Weisberg E, Shangold GA, Fisher AC, Creasy GW. Contraceptive efficacy and cycle control with the Ortho Evra/Evra transdermal system: the analysis of pooled data. Fertil Steril. 2002; 77(2 Suppl 2):S13-S18.

44. Foegh M, Archer DF, Stanczyk FZ, Rubin A, Mishell DR. Ovarian activity in obese and nonobese women treated with three transdermal contraceptive patches delivering three different doses of ethinyl estradiol and levonorgestrel. Contraception. 2013;87(2):201-211.

45. Horne FM, Blithe DL. Progesterone receptor modulators and the endometrium: changes and consequences. Hum Reprod Update. 2007;13(6):567-580.

46. Mutter GL, Bergeron C, Deligdisch L, et al. The spectrum of endometrial pathology induced by progesterone receptor modulators. Mod Pathol. 2008;21(5):591-598.

47. Watson Pharmaceuticals. Efficacy and Safety Study of Norethindrone Acetate Transdermal Delivery System in Contraception (Simplify). Available from: http://clinicaltrials.gov/show/NCT01140217. NLM identifier: NCT01140217. Accessed January 9, 2014.
48. Heger-Mahn D, Warlimont C, Faustmann T, Gerlinger C, Klipping C. Combined ethinylestradiol/gestodene contraceptive patch: two-center, open-label study of ovulation inhibition, acceptability and safety over two cycles in female volunteers. Eur J Contracept Reprod Health Care. 2004;9(3):173-181.

49. Junge W, Heger-Mahn D, Trummer D, Merz M. Investigation of the hemostatic effect of a transdermal patch containing $0.55 \mathrm{mg}$ ethinyl estradiol and $2.1 \mathrm{mg}$ gestodene compared with a monophasic oral contraceptive containing $0.03 \mathrm{mg}$ ethinyl estradiol and $0.15 \mathrm{mg}$ levonorgestrel: an open-label, randomized, crossover study. Drugs $R D$. 2013;13(3):223-233.

50. Haukkamaa M, Laurikka-Routti M, Heikinheimo O. Transdermal absorption of the progestin ST-1435: therapeutic serum steroid concentrations and high excretion of the steroid in saliva. Contraception. 1991;44(3):269-276.

51. Kumar N, Koide SS, Tsong YY, Sundaram K. Nestorone: a progestin with a unique pharmacological profile. Steroids. 2000;65(10-11): 629-636.

52. Sitruk-Ware R, Small M, Kumar N, Tsong YY, Sundaram K, Jackanicz T. Nestorone: clinical applications for contraception and HRT. Steroids. 2003;68(10-13):907-913.

53. Fraser IS, Weisberg E, Kumar N, et al. An initial pharmacokinetic study with a Metered Dose Transdermal Systemfor delivery of the progestogen Nestorone as a possible future contraceptive. Contraception. 2007;76(6):432-438.

54. Sitruk-Ware R, Nath A, Mishell DR. Contraception technology: past, present and future. Contraception. 2013;87(3):319-330.

55. Brache V, Mishell DR, Lahteenmaki P, et al. Ovarian function during use of vaginal rings delivering three different doses of Nestorone. Contraception. 2001;63(5):257-261.

56. Guazzelli CA, Barreiros FA, Barbosa R, de Araújo FF, Moron AF. Extended regimens of the vaginal contraceptive ring: cycle control. Contraception. 2009;80(5):430-435.

57. Barreiros FA, Guazzelli CA, Barbosa R, de Assis F, de Araújo FF. Extended regimens of the contraceptive vaginal ring: evaluation of clinical aspects. Contraception. 2010;81(3):223-225.

58. Szarewski A. High acceptability and satisfaction with NuvaRing use. Eur J Contracept Reprod Health Care. 2002;7 Suppl 2:31-36; discussion 37-39.

59. Ahrendt HJ, Nisand I, Bastianelli C, et al. Efficacy, acceptability and tolerability of the combined contraceptive ring, NuvaRing, compared with an oral contraceptive containing 30 microg of ethinyl estradiol and $3 \mathrm{mg}$ of drospirenone. Contraception. 2006;74(6): 451-457.

60. Lopez LM, Grimes DA, Gallo MF, Stockton LL, Schulz KF. Skin patch and vaginal ring versus combined oral contraceptives for contraception. Cochrane Database Syst Rev. 2013;4:CD003552.

61. Nath A, Sitruk-Ware R. Progesterone vaginal ring for contraceptive use during lactation. Contraception. 2010;82(5):428-434.

62. Massai R, Miranda P, Valdés P, et al. Preregistration study on the safety and contraceptive efficacy of the progesterone-releasing vaginal ring in Chilean nursing women. Contraception. 1999;60(1): 9-14.

63. Sivin I, Díaz S, Croxatto HB, et al. Contraceptives for lactating women: a comparative trial of a progesterone-releasing vaginal ring and the copper T 380A IUD. Contraception. 1997;55(4): 225-232.

64. Massai R, Quinteros E, Reyes MV, et al. Extended use of a progesterone-releasing vaginal ring in nursing women: a phase II clinical trial. Contraception. 2005;72(5):352-357.

65. Indian Council of Medical Research. Evaluation of Progesterone vaginal ring v/s Cu T $380 \mathrm{~A}$ IUD in lactating women. Available from: http://www.ctri.nic.in/Clinicaltrials/pmaindet2.php?trialid=3133. CTRI number: CTRI/2011/07/001874. Accessed January 9, 2014.

66. Brache V, Mishell DR, Lahteenmaki P, et al. Ovarian function during use of vaginal rings delivering three different doses of Nestorone. Contraception. 2001;63(5):257-261. 
67. Brache V, Payán LJ, Faundes A. Current status of contraceptive vaginal rings. Contraception. 2013;87(3):264-272.

68. Sivin I, Mishell DR, Alvarez F, et al. Contraceptive vaginal rings releasing Nestorone and ethinylestradiol: a 1-year dose-finding trial. Contraception. 2005;71(2):122-129.

69. Gilliam ML, Neustadt A, Kozloski M, Mistretta S, Tilmon S, Godfrey E. Adherence and acceptability of the contraceptive ring compared with the pill among students: a randomized controlled trial. Obstet Gynecol. 2010;115(3):503-510.

70. Sitruk-Ware R, Merkatz R, Sussman H, Variano B. A one year contraceptive vaginal ring delivering Nestorone and ethinyl-estradiol. In: Program and abstracts of the 11th Congress of the European Society of Contraception and Reproductive Health; May 19-22, 2010; The Hague, The Netherlands. Abstract SS4-2.

71. Merkatz R, Sussman H, Sivin I, et al. Preliminary results from a phase III study of the Nestorone/ethinyl estradiol contraceptive vaginal ring: a new, long acting (one year) user controlled contraceptive method. In: Program and abstracts of the 11th Congress of the European Society of Contraception and Reproductive Health; May 19-22, 2010; The Hague, The Netherlands. Abstract FC-01.

72. Johansson ED, Sitruk-Ware R. New delivery systems in contraception: vaginal rings. Am J Obstet Gynecol. 2004;190(Suppl 4):S54-S59.

73. Eunice Kennedy Shriver National Institute of Child Health and Human Development (NICHD). A Dose-finding Study to Evaluate the Effect of a Contraceptive Vaginal Ring, Releasing Nestorone ${ }^{\circledR}$ and Estradiol, on Cycle Control, Ovulation Inhibition, and Pharmacokinetics in Normal Cycling Women. Available from: http://clinicaltrials.gov/show/ NCT01586000. NLM identifier: NCT01586000. Accessed January 9, 2014.

74. Jensen JT. Vaginal ring delivery of selective progesterone receptor modulators for contraception. Contraception. 2013;87(3):314-318.

75. Cyclofem ${ }^{\circledR}$ [webpage on the Internet]. Khlong Luang District: Concept Foundation; 2009. Available from: http:/www.conceptfoundation.org/ hormonal-contraception.php. Accessed January 9, 2014

76. Luukkainen T. Levonorgestrel-releasing intrauterine device. Ann Med. 1990;22(2):85-90.

77. Luukkainen T. The levonorgestrel intrauterine system: therapeutic aspects. Steroids. 2000;65(10-11):699-702.

78. Odlind V. Long-term experience of a levonorgestrel-releasing intrauterine system. Eur J Contracept Reprod Health Care. 1996;1(4): 319-323.

79. Gemzell-Danielsson K, Schellschmidt I, Apter D. A randomized, phase II study describing the efficacy, bleeding profile, and safety of two low-dose levonorgestrel-releasing intrauterine contraceptive systems and Mirena. Fertil Steril. 2012;97(3):616-622. e1.

80. Bahamondes MV, Hidalgo MM, Bahamondes L, Monteiro I. Ease of insertion and clinical performance of the levonorgestrel-releasing intrauterine system in nulligravidas. Contraception. 2011;84(5): e11-e16.

81. Medicines360. A study of levonorgestrel-releasing intrauterine system for long-term, reversible contraception. Available from: http://www. clinicaltrials.gov/ct2/show/NCT00995150?term=medicines360\&rank =1. NLM identifier: NCT00995150. Accessed January 9, 2013.

82. Goodman AL, Hodgen GD. Progesterone receptor antagonists. In: Adashi EY, Rock JA, Rosenwaks Z, editors. Reproductive Endocrinology, Surgery, and Technology. Philadelphia: Lippincott-Raven Publishers; 1996:548-558.

83. Elger W, Bartley J, Schneider B, Kaufmann G, Schubert G, Chwalisz K. Endocrine pharmacological characterization of progesterone antagonists and progesterone receptor modulators with respect to PR-agonistic and antagonistic activity. Steroids. 2000;65(10-11): 713-723.

84. Attardi BJ, Burgenson J, Hild SA, Reel JR, Blye RP. CDB-4124 and its putative monodemethylated metabolite, CDB-4453, are potent antiprogestins with reduced antiglucocorticoid activity: in vitro comparison to mifepristone and CDB-2914. Mol Cell Endocrinol. 2002;188(1-2): 111-123.
85. Blithe DL, Nieman LK, Blye RP, Stratton P, Passaro M. Development of the selective progesterone receptor modulator CDB-2914 for clinical indications. Steroids. 2003;68(10-13):1013-1017.

86. Gainer EE, Ulmann A. Pharmacologic properties of CDB(VA)-2914. Steroids. 2003;68(10-13):1005-1011.

87. Brenner RM, Slayden OD, Nath A, Tsong YY, Sitruk-Ware R. Intrauterine administration of CDB-2914 (Ulipristal) suppresses the endometrium of rhesus macaques. Contraception. 2010;81(4): 336-342.

88. Chwalisz K, Garg R, Brenner R, Slayden O, Winkel C, Elger W. Role of nonhuman primate models in the discovery and clinical development of selective progesterone receptor modulators (SPRMs). Reprod Biol Endocrinol. 2006;4 Suppl 1:S8.

89. Meirik O, Fraser IS, d'Arcangues C; WHO Consultation on Implantable Contraceptives for Women. Implantable contraceptives for women. Hum Reprod Update. 2003;9(1):49-59.

90. Mansour D, Bahamondes L, Critchley H, Darney P, Fraser IS. The management of unacceptable bleeding patterns in etonogestrelreleasing contraceptive implant users. Contraception. 2011;83(3): 202-210.

91. Lähteenmäki P, Weiner E, Lähteenmäki P, Johansson E, Luukkainen T. Contraception with subcutaneous capsules containing ST-1435. Pituitary and ovarian function and plasma levels of ST-1435. Contraception. 1981;23(1):63-75.

92. Díaz S, Schiappacasse V, Pavez M, et al. Clinical trial with Nestorone subdermal contraceptive implants. Contraception. 1995;51(1): 33-38.

93. Sivin I, Croxatto H, Bahamondes L, et al. Two-year performance of a Nestorone-releasing contraceptive implant: a three-center study of 300 women. Contraception. 2004;69(2):137-144.

94. International Consortium for Emergency Contraception [homepage on the Internet]. New York: International Consortium for Emergency Contraception; 2014. Available from: http://www.cecinfo.org/. Accessed January 22, 2013.

95. Trussell J, Rodríguez G, Ellertson C. New estimates of the effectiveness of the Yuzpe regimen of emergency contraception. Contraception. 1998;57(6):363-369.

96. Task Force on Postovulatory Methods of Fertility Regulation. Randomised controlled trial of levonorgestrel versus the Yuzpe regimen of combined oral contraceptives for emergency contraception. Lancet. 1998;352(9126):428-433.

97. von Hertzen H, Piaggio G, Van Look PF. Emergency contraception with levonorgestrel or the Yuzpe regimen. Task Force on Postovulatory Methods of Fertility Regulation. Lancet. 1998; 352(9144):1939.

98. Wu S, Godfrey EM, Wojdyla D, et al. Copper T380A intrauterine device for emergency contraception: a prospective, multicentre, cohort clinical trial. BJOG. 2010;117(10):1205-1210.

99. Creinin MD, Schlaff W, Archer DF, et al. Progesterone receptor modulator for emergency contraception: a randomized controlled trial. Obstet Gynecol. 2006;108(5):1089-1097.

100. Glasier AF, Cameron ST, Fine PM, et al. Ulipristal acetate versus levonorgestrel for emergency contraception: a randomised non-inferiority trial and meta-analysis. Lancet. 2010;375(9714):555-562.

101. Fine P, Mathé H, Ginde S, Cullins V, Morfesis J, Gainer E. Ulipristal acetate taken 48-120 hours after intercourse for emergency contraception. Obstet Gynecol. 2010;115(2 Pt 1): 257-263.

102. Brache V, Cochon L, Deniaud M, Croxatto HB. Ulipristal acetate prevents ovulation more effectively than levonorgestrel: analysis of pooled data from three randomized trials of emergency contraception regimens. Contraception. 2013;88(5): 611-618.

103. Pall M, Fridén BE, Brännström M. Induction of delayed follicular rupture in the human by the selective COX-2 inhibitor rofecoxib: a randomized double-blind study. Hum Reprod. 2001;16(7): 1323-1328. 
104. Bata MS, Al-Ramahi M, Salhab AS, Gharaibeh MN, Schwartz J. Delay of ovulation by meloxicam in healthy cycling volunteers: A placebo-controlled, double-blind, crossover study. J Clin Pharmacol. 2006;46(8):925-932.

105. Richards JS. Perspective: the ovarian follicle - a perspective in 2001. Endocrinology. 2001;142(6):2184-2193.

106. Jesam C, Salvatierra AM, Schwartz JL, Croxatto HB. Suppression of follicular rupture with meloxicam, a cyclooxygenase-2 inhibitor: potential for emergency contraception. Hum Reprod. 2010;25(2):368-373.

107. Edelman AB, Jensen JT, Hennebold JD. A nonhormonal model for emergency contraception: prostaglandin synthesis inhibitor effects on luteal function and lifespan, a pilot study. Contraception. 2010;81(6): 496-500.

108. Edelman AB, Jensen JT, Doom C, Hennebold JD. Impact of the prostaglandin synthase-2 inhibitor celecoxib on ovulation and luteal events in women. Contraception. 2013;87(3):352-357.

109. Pearce-Pratt R, Phillips DM. Sulfated polysaccharides inhibit lymphocyte-to-epithelial transmission of human immunodeficiency virus-1. Biol Reprod. 1996;54(1):173-182.

110. Sitruk-Ware R, Brache V, Maguire R, et al. Pharmacokinetic study to compare the absorption and tolerability of two doses of levonorgestrel following single vaginal administration of levonorgestrel in Carraguard gel: a new formulation for "dual protection" contraception. Contraception. 2007;75(6):454-460.

111. Elias CJ, Coggins C, Alvarez F, et al. Colposcopic evaluation of a vaginal gel formulation of iota-carrageenan. Contraception. 1997;56(6): 387-389.

112. Coggins C, Blanchard K, Alvarez F, et al. Preliminary safety and acceptability of a carrageenan gel for possible use as a vaginal microbicide. Sex Transm Infect. 2000;76(6):480-483.

113. Victor A, Johansson ED. Plasma levels of d-norgestrel and ovarian function in women using intravaginal rings impregnated with dlnorgestrel for several cycles. Contraception. 1976;14(2):215-226.
114. Brache V, Croxatto H, Sitruk-Ware R, et al. Effect of a single vaginal administration of levonorgestrel in Carraguard gel on the ovulatory process: a potential candidate for "dual protection" emergency contraception. Contraception. 2007;76(2):111-116.

115. Brache V, Croxatto H, Kumar N, et al. Effect of sexual intercourse on the absorption of levonorgestrel after vaginal administration of $0.75 \mathrm{mg}$ in Carraguard gel: a randomized, cross-over, pharmacokinetic study. Contraception. 2009;79(2):150-154.

116. Taylor DJ, Lendvay A, Halpern V, et al. A single-arm study to evaluate the efficacy, safety and acceptability of pericoital oral contraception with levonorgestrel. Contraception. Epub November 26, 2013,

117. Woolcock JG, Critchley HO, Munro MG, Broder MS, Fraser IS. Review of the confusion in current and historical terminology and definitions for disturbances of menstrual bleeding. Fertil Steril. 2008;90(6):2269-2280.

118. Grimes DA, Schulz KF, Raymond EG. Surrogate end points in women's health research: science, protoscience, and pseudoscience. Fertil Steril. 2010;93(6):1731-1734.

119. Santelli J, Rochat R, Hatfield-Timajchy K, et al; Unintended Pregnancy Working Group. The measurement and meaning of unintended pregnancy. Perspect Sex Reprod Health. 2003;35(2):94-101.

120. Gipson JD, Koenig MA, Hindin MJ. The effects of unintended pregnancy on infant, child, and parental health: a review of the literature. Stud Fam Plann. 2008;39(1):18-38.

121. Sedgh G, Singh S, Shah IH, Ahman E, Henshaw SK, Bankole A. Induced abortion: incidence and trends worldwide from 1995 to 2008. Lancet. 2012;379(9816):625-632.

122. World Health Organization. Unsafe Abortion: Global and Regional Estimates of the Incidence of Unsafe Abortion and Associated Mortality in 2008. 6th ed. Geneva: World Health Organization, 2011. Available from: http://whqlibdoc.who.int/publications/2011/9789241501118_ eng.pdf. Accessed August 25, 2013.
International Journal of Women's Health

\section{Publish your work in this journal}

The International Journal of Women's Health is an international, peerreviewed open-access journal publishing original research, reports, editorials, reviews and commentaries on all aspects of women's healthcare including gynecology, obstetrics, and breast cancer. The manuscript management system is completely online and includes
Dovepress

a very quick and fair peer-review system, which is all easy to use. Visit http://www.dovepress.com/testimonials.php to read real quotes from published authors. 